\title{
Management and outcome of cardiogenic shock complicating acute myocardial infarction in hospitals with and without on-site catheterisation facilities
}

I M Barbash, S Behar, A Battler, D Hasdai, V Boyko, S Gottlieb, J Leor, for the Israeli Thrombolytic Survey Group

\begin{abstract}
Objective-To determine whether the availability of on-site catheterisation and revascularisation facilities influenced hospital management and outcome of patients with acute myocardial infarction complicated by cardiogenic shock.

Methods-Patients with acute myocardial infarction were enrolled prospectively in four nationwide surveys during 1992, 1994, 1996, and 1998. The characteristics, management, and outcome of patients with cardiogenic shock were compared between hospitals with on-site catheterisation facilities (group 1; 18 hospitals) and without such facilities (group 2; 8 hospitals).

Results-Of 5351 patients with acute myocardial infarction, 254 (4.7\%) developed cardiogenic shock. Group 1 patients ( $\mathrm{n}=186$ of $3854 ; 4.6 \%$ ) were younger (mean (SD) age, 69.6 (12) v 73.7 (10) years, $\mathrm{p}=0.006)$ and had a lower proportion of women $(36 \% v 52 \%, \mathrm{p}=0.03)$ than group $2(n=68$ of $1243 ; 5.2 \%)$. There was no difference in other characteristics including the use of thrombolysis. Group 1 patients more often underwent coronary angiography $(26 \% v 4 \%$, $\mathrm{p}<0.001)$, angioplasty $(21 \% v 4 \%, \mathrm{p}=0.002)$, and intra-aortic balloon counterpulsation $(28 \%$ $v 4 \%, \mathrm{p}<0.001)$. Seven day mortality was lower among group 1 than among group 2 patients $(61 \% v 77 \%, \mathrm{p}=0.02)$, even after age and sex adjustment (odds ratio (OR) $0.54 ; 95 \%$ confidence interval (CI) 0.28 to 1.02$)$. This outcome benefit persisted at 30 days $(74 \% v 88 \%$, $\mathrm{p}=0.01 ;$ OR $0.45,95 \%$ CI 0.18 to 0.98$)$, and at 6 months $(80 \% v 90 \%, p=0.06 ;$ OR $0.57,95 \%$ CI 0.22 to 1.33 ).

Conclusions-The greater use of invasive and interventional procedures in hospitals with catheterisation facilities is associated with improved survival of patients with acute myocardial infarction complicated by cardiogenic shock. Immediate availability of invasive care facilities will improve the outcome of cardiogenic shock in the community setting.
\end{abstract}

(Heart 2001;86:145-149)

Keywords: percutaneous transluminal coronary angioplasty; heart failure; myocardial infarction; cardiogenic shock

\section{Cardiology \\ Department, Soroka \\ Medical Centre, \\ Faculty of Health \\ Sciences, Ben-Gurion \\ University of the \\ Negev, Beer-Sheva, \\ Israel \\ I M Barbash \\ J Leor}

Neufeld Cardiac

Research Institute,

Sheba Medical Centre,

Tel-Hashomer, Israel

$S$ Behar

V Boyko

S Gottlieb

Cardiology

Department, Rabin

Medical Centre,

Petah-Tikva, Israel

A Battler

D Hasdai

Correspondence to:

Dr Leor

leori@post.tau.ac.il

Accepted 13 February 2001
Immediate aggressive treatment combined with early revascularisation is thought to be associated with greater myocardial salvage and better survival of patients with cardiogenic shock complicating acute myocardial infarction. ${ }^{1}$ Several non-randomised retrospective observations have suggested that urgent percutaneous transluminal coronary angioplasty (PTCA) reduces mortality in patients with acute myocardial infarction complicated by cardiogenic shock. ${ }^{2-5}$ The greater use of interventional procedures is thought to be responsible for the improved outcome of cardiogenic shock patients in the USA compared with other countries in certain studies. ${ }^{6}$

However, the relative benefit of interventional procedures in cardiogenic shock in a community setting - in which access to a catheterisation facility and operator expertise is less uniform than in a trial setting-is still unknown. ${ }^{7}$ This question has important medical, organisational, cost, and training implications. We therefore performed the present study to determine the effect of the availability of on-site catheterisation facilities on the treatment and outcome of patients with cardiogenic shock in a broad spectrum of hospital settings, ranging from rural community hospitals to large tertiary centres. Four national Israeli surveys conducted in 1992, 1994, 1996, and 1998 enrolled all patients with acute myocardial infarction admitted to coronary care units (CCU). We examined this unselected nationwide cohort to determine whether the availability of on-site catheterisation and revascularisation facilities influenced the hospital management and outcome of patients with acute myocardial infarction complicated by cardiogenic shock.

\section{Methods}

PATIENTS

Patients admitted to all 26 CCUs in Israel were prospectively enrolled in four national surveys which were conducted in January and February of 1992 (25 CCUs), January and February of 1994 (25 CCUs), January and February and May to July of 1996 (26 CCUs), and January and February of 1998 (26 CCUs). Details of the registry protocol have been described previously. ${ }^{8}$ Briefly, the patients' demographic data, medical history, hospital management 
and complications, and 30 day and six month follow up were recorded prospectively on a predefined survey form.

The medical records of all patients in Killip class IV on admission or with a recorded hospital diagnosis of cardiogenic shock were reviewed by two of the authors (IMB and JL), in order to validate the diagnosis of cardiogenic shock at any time during the hospitalisation and to exclude other causes of shock. The time of shock onset was analysed relative to the hospital admission. The onset of shock before admission or upon arrival at the hospital was regarded as time zero.

Patients were admitted to the nearest available hospital and were referred for invasive cardiac procedures at the discretion of the attending physician. Success of the procedure was determined by the operating physician. Special attention was given to verifying that patients who underwent invasive procedures did so during the shock and not after recovery. All surviving patients were seen or contacted by telephone at 30 days. Six month mortality data were obtained from records of the Ministry of Internal Affairs.

Patients were divided into two groups: those admitted to the 18 hospitals with on-site catheterisation facilities and those admitted to the eight hospitals without catheterisation facilities. Clinical characteristics and outcome were compared retrospectively between the defined groups.

CARDIOGENIC SHOCK CRITERIA

Cardiogenic shock criteria were modified from the SHOCK (should we emergently revascularise occluded coronaries for cardiogenic shock?) trial $^{9}$ and the GUSTO-I (global utilization of streptokinase and tissue plasminogen activator for occluded coronary arteries) trial, ${ }^{4}$ and included patients with signs predominantly of severe left ventricular dysfunction: systolic blood pressure of $90 \mathrm{~mm} \mathrm{Hg}$ or less for more than one hour despite a fluid challenge, together with clinical signs of tissue hypoperfusion. Among patients who were monitored with a pulmonary artery catheter, cardiogenic shock criteria included a cardiac index of $<2.21 / \mathrm{min} / \mathrm{M}$ and a pulmonary capillary wedge pressure $>18 \mathrm{~mm} \mathrm{Hg}$. Patients in shock because of correctable bradyor tachyarrhythmias or rupture of the left ventricular free wall, interventricular septum, or papillary muscle were excluded from the analysis.

STATISTICAL ANALYSIS

Statistical analysis was performed using SAS software. ${ }^{10}$ Continuous variables are expressed as mean (SD), or as median (range) where appropriate, and differences were calculated by a two tailed $t$ test or Wilcoxon rank-sum test. Differences between categorical data were analysed by the $\chi^{2}$ test, and a probability value of $\mathrm{p}<0.05$ was considered significant. KaplanMeier survival curves were constructed using the SAS Lifetest procedure.

Multivariate logistic regression analyses were performed to assess the independent effect of different variables on outcome using the SAS Logistic procedure. To ascertain whether there was an independent association between the availability of catheterisation facilities and invasive resource utilisation and outcome, a multivariate logistic regression analysis was done using the SAS Logistic procedure. Additionally, a multivariate model adjusting for age and sex was conducted in order to assess the independent effect of PTCA on mortality.

\section{Results}

PATIENT CHARACTERISTICS

Of the 5351 patients with acute myocardial infarction admitted to the 26 CCUs during the four national surveys, $254(4.7 \%)$ had a confirmed diagnosis of cardiogenic shock. The mean (SD) age of these 254 patients was 71 (12) years, and $103(43.5 \%)$ of them were women.

Of the 3854 patients admitted to 18 hospitals with on-site catheterisation facilities, $186(4.6 \%)$ had cardiogenic shock. Among the 1243 patients admitted to eight hospitals without catheterisation facilities, $68(5.2 \%)$ had cardiogenic shock $(\mathrm{p}=0.4)$.

Table 1 compares clinical characteristics of the two groups. Patients admitted to hospitals with catheterisation facilities were younger (69.2 (12) $v 73.7$ (10) years, $\mathrm{p}=0.005)$ and the proportion of women was lower $(37 \% v$ $52 \%, \mathrm{p}=0.03)$. Other baseline characteristics were similar. Median time from admission to shock evolution was similar in the two groups, and a similar proportion of patients were already in cardiogenic shock on admission $(57 \%$ v 54\%, respectively). The clinical characteristics of the patients in the two groups were comparable, including infarct location and peak creatine phosphokinase levels.

Table 1 Baseline and clinical characteristics of patients with cardiogenic shock treated in hospitals with versus those without catheterisation facilities

\begin{tabular}{|c|c|c|c|}
\hline & $\begin{array}{c}\text { Facilities } \\
(n=186)\end{array}$ & $\begin{array}{l}\text { No facilities } \\
(n=68)\end{array}$ & $p$ Value \\
\hline Age (years) & $69.2(12)$ & $73.7(10)$ & 0.005 \\
\hline Women & $68(37 \%)$ & $35(52 \%)$ & 0.03 \\
\hline \multicolumn{4}{|l|}{ Medical history } \\
\hline Previous MI & $72(39 \%)$ & $24(35 \%)$ & 0.58 \\
\hline Angina & $65(35 \%)$ & $26(38 \%)$ & 0.63 \\
\hline Hypertension & $88(47 \%)$ & $34(50 \%)$ & 0.70 \\
\hline Diabetes & $73(39 \%)$ & $31(46 \%)$ & 0.36 \\
\hline Hyperlipidaemia & $36(19 \%)$ & $8(12 \%)$ & 0.16 \\
\hline Smoking habit & $38(20 \%)$ & $12(18 \%)$ & 0.62 \\
\hline \multicolumn{4}{|l|}{ Clinical features } \\
\hline Shock on admission $\dagger$ & $94(57 \%)$ & $34(54 \%)$ & 0.91 \\
\hline \multicolumn{4}{|l|}{ Time to shock (days) } \\
\hline Median & 0 & 0 & 0.78 \\
\hline 25 th -75 th centile & $0-1$ & $0-1$ & \\
\hline Anterior wall MI & $96(52 \%)$ & $37(54 \%)$ & 0.69 \\
\hline Right ventricular MI & $24(13 \%)$ & $7(10 \%)$ & 0.55 \\
\hline \multicolumn{4}{|l|}{ CPK level (U/l) } \\
\hline Median & 1422 & 1024 & 0.13 \\
\hline 25 th -75 th centile & $690-2804$ & $350-2072$ & \\
\hline \multicolumn{4}{|l|}{ Complications } \\
\hline Recurrent ischaemia & $17(9 \%)$ & $4(6 \%)$ & 0.40 \\
\hline Recurrent MI & $13(7 \%)$ & $5(7 \%)$ & 0.92 \\
\hline Atrial fibrillation & $39(21 \%)$ & $15(22 \%)$ & 0.85 \\
\hline $\mathrm{II}^{\circ}-\mathrm{III}^{\circ} \mathrm{AV}$ block & $42(23 \%)$ & $22(32 \%)$ & 0.11 \\
\hline $\mathrm{VT} / \mathrm{VF}$ & $66(35 \%)$ & $16(23 \%)$ & 0.07 \\
\hline
\end{tabular}

Values are $\mathrm{n}(\%)$ or mean (SD)

†Missing data for 27 patients.

$\mathrm{AV}$, atrioventricular; $\mathrm{CPK}$, creatine phosphokinase; $\mathrm{MI}$, myocardial infarction; VF, ventricular fibrillation; VT, ventricular tachycardia. 
Table 2 In-hospital treatment and procedures in patients with cardiogenic shock managed in hospitals with versus those without catheterisation facilities

\begin{tabular}{llll}
\hline & $\begin{array}{l}\text { Facilities } \\
(n=186)\end{array}$ & $\begin{array}{l}\text { No facilities } \\
(n=68)\end{array}$ & $p$ Value \\
\hline Drugs & & & \\
$\quad$ Aspirin & $101(54 \%)$ & $31(46 \%)$ & 0.22 \\
$\quad$ Digoxin & $37(20 \%)$ & $12(18 \%)$ & 0.69 \\
Nitrates & $96(52 \%)$ & $33(49 \%)$ & 0.66 \\
ACE inhibitors & $54(29 \%)$ & $14(21 \%)$ & 0.18 \\
$\quad \begin{array}{l}\text { Blockers } \\
\text { Amiodarone }\end{array}$ & $30(16 \%)$ & $7(10 \%)$ & 0.24 \\
Abciximab (ReoPro) & $9(5 \%)$ & $2(3 \%)$ & 0.51 \\
Thrombolysis & $56(30 \%)$ & $0(0 \%)$ & 0.22 \\
Angiography & $49(26 \%)$ & $3(4 \% \%)$ & 0.22 \\
PTCA & $39(21 \%)$ & $3(4 \%)$ & 0.001 \\
$\quad$ Primary PTCA & $34(87 \%)$ & $2(66 \%)$ & 0.05 \\
Successful PTCA & $31 / 39(80 \%)$ & $2 / 3(67 \%)$ & 0.60 \\
Time from shock (h) & & & $<0.001$ \\
$\quad$ Median & 0 & 0 & \\
$\quad$ 25th-75th centile & $0-0$ & $0-3$ & \\
IABP & $52(28 \%)$ & $3(4 \%)$ & $<0.001$ \\
CABG & $8(4 \%)$ & $1(1 \%)$ & 0.28 \\
\hline
\end{tabular}

Values are $\mathrm{n}(\%)$.

$\mathrm{ACE}$, angiotensin converting enzyme; $\mathrm{CABG}$, coronary artery bypass graft; IABP, intra-aortic balloon pump; PTCA, percutaneous transluminal coronary angioplasty.

The incidence of in-hospital complications was similar (table 1), including rates of atrioventricular block events, recurrent ischaemia, and reinfarction.

IN-HOSPITAL MANAGEMENT

No difference was found in the use of drugs and thrombolysis $(30 \%$ v 38\%, p = 0.2) between the patients admitted to hospitals with and without catheterisation facilities (table 2).

\section{Coronary angiography}

Diagnostic coronary angiography was performed in $49(26 \%)$ of the patients treated in hospitals with catheterisation facilities and in three $(4 \%)$ of the patients treated in hospitals without such facilities $(\mathrm{p}<0.001$, table 2$)$. Of the patients selected for coronary angiography, three vessel disease was documented in 21 patients, left main coronary artery disease in seven, two vessel disease in 10 , and single vessel disease in 14 .

Revascularisation and invasive procedures Patients admitted to hospitals with on-site catheterisation facilities more often underwent invasive procedures, and 39 patients $(21 \%)$ were referred for PTCA (table 2). Of these, 34 $(87 \%)$ underwent primary PTCA, and five underwent rescue PTCA. The PTCA success rate in this group was $80 \%$. Patients admitted to hospitals without catheterisation facilities were less likely to undergo PTCA $(p=0.002)$; one patient underwent rescue PTCA and two were referred for primary PTCA (table 2). All

Table 3 Short and long term outcome of patients with cardiogenic shock treated in hospitals with versus those without catheterisation facilities

\begin{tabular}{lllll}
\hline Mortality & Facilities $(n=186)$ & No facilities $(n=68)$ & $p$ Value & OR (95\% CI)t \\
\hline 7 day & $113(61 \%)$ & $52(77 \%)$ & 0.02 & $0.54(0.28$ to 1.02$)$ \\
30 day & $137(74 \%)$ & $60(88 \%)$ & 0.01 & $0.45(0.18$ to 0.98$)$ \\
60 day & $147(79 \%)$ & $61(90 \%)$ & 0.05 & $0.56(0.22$ to 1.30$)$ \\
6 month & $148(80 \%)$ & $61(90 \%)$ & 0.06 & $0.57(0.22$ to 1.33$)$ \\
\hline
\end{tabular}

Values are $\mathrm{n}(\%)$.

tOdds ratio, adjusted for age and sex.

$\mathrm{CI}$, confidence interval.

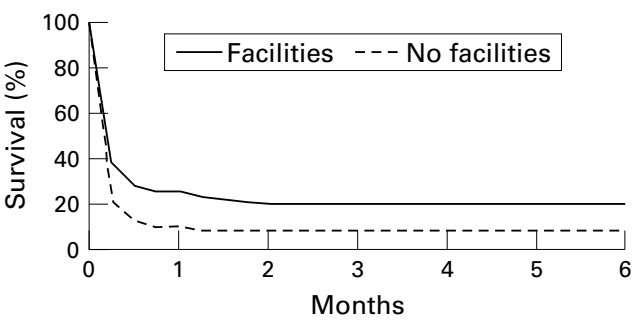

Figure 1 Kaplan-Meier survival curves of cardiogenic shock patients admitted to hospitals with or without catheterisation facilities $\left(p_{\log -\text { rank }}=0.001\right)$.

of these patients were treated with an intraaortic balloon pump (IABP). IABP was used more often among patients admitted to hospitals with catheterisation facilities $(28 \% v 4 \%$, $\mathrm{p}<0.001)$.

\section{ASSOCIATION BETWEEN CATHETERISATION}

FACILITIES AND OUTCOME

These results are shown in table 3 and fig 1. Overall seven day mortality for all patients with cardiogenic shock was $65 \%$. Patients treated in hospitals with on-site catheterisation facilities experienced lower seven day $(61 \%$ v $77 \%$, $\mathrm{p}=0.02), 30$ day $(74 \% v 88 \%, \mathrm{p}=0.01)$, and two month mortality $(79 \%$ v $90 \%, \mathrm{p}=0.05)$ compared with patients treated in hospitals without such facilities. This benefit remained significant after adjustment for age and sex, with an odds ratio (OR) of 0.54 (95\% confidence interval (CI) 0.28 to 1.02 ) at seven days, and 0.45 (95\% CI 0.18 to 0.98$)$ at 30 days. At the two month (OR 0.56, 95\% CI 0.22 to 1.30 ) and six month follow up (OR 0.57, $95 \%$ CI 0.22 to 1.33 ) the independent association of outcome benefit and availability of on-site catheterisation facilities decreased.

PRIMARY AND RESCUE PTCA

Subgroup analysis of patients from group 1 (hospitals with on-site catheterisation facilities) showed that those who underwent PTCA were significantly younger (61 (12) v 71 (11) years, $\mathrm{p}<0.001)$ and more likely to be male $(74 \% v$ $61 \%, \mathrm{p}=0.1$ ) than the remaining patients in that group (table 4). PTCA patients also had lower rates of diabetes mellitus $(28 \% v 42 \%$, $\mathrm{p}=0.1)$ and were less likely to have a history of hypertension $(26 \%$ v 53\%, p=0.002) and

Table 4 Characteristics of patients with cardiogenic shock selected versus not selected for percutaneous transluminal coronary angioplasty (PTCA)

\begin{tabular}{llll}
\hline & $\begin{array}{l}P T C A \\
(n=39)\end{array}$ & $\begin{array}{l}\text { No PTCA } \\
(n=147)\end{array}$ & p Value \\
\hline Age (years) & $61.6(12)$ & $71.2(10)$ & $<0.001$ \\
Women & $10(26 \%)$ & $58(39 \%)$ & 0.11 \\
$\begin{array}{l}\text { Medical history } \\
\quad \text { Previous MI }\end{array}$ & $11(29 \%)$ & $61(41 \%)$ & 0.15 \\
$\quad$ Angina & $15(38 \%)$ & $50(34 \%)$ & 0.61 \\
$\quad$ Hypertension & $10(26 \%)$ & $78(53 \%)$ & 0.002 \\
$\quad \begin{array}{l}\text { Diabetes } \\
\text { Hyperlipidaemia }\end{array}$ & $11(28 \%)$ & $62(42 \%)$ & 0.11 \\
$\quad$ Smoking habit & $14(36 \%)$ & $27(18 \%)$ & 0.51 \\
Clinical features & & $24(16 \%)$ & 0.007 \\
$\quad$ Anterior wall MI & $24(61 \%)$ & $72(49 \%)$ & 0.16 \\
$\quad$ Right ventricular MI & $5(13 \%)$ & $19(13 \%)$ & 0.99 \\
Thrombolysis & $10(26 \%)$ & $46(31 \%)$ & 0.49 \\
IABP & $28(72 \%)$ & $24(16 \%)$ & $<0.001$ \\
& & &
\end{tabular}

Values are $\mathrm{n}(\%)$ or mean (SD).

IABP, intra-aortic balloon pump; MI, myocardial infarction. 
Table 5 Percutaneous transluminal coronary angioplasty (PTCA) and mortality from cardiogenic shock in hospitals with on-site catheterisation facilities

\begin{tabular}{lllll}
\hline & $\begin{array}{l}\text { No PTCA } \\
(n=147)\end{array}$ & $\begin{array}{l}\text { PTCA } \\
(n=39)\end{array}$ & $\begin{array}{l}\text { Successful PTCA } \\
(n=33)\end{array}$ & $\begin{array}{l}\text { Unsuccessful } \\
\text { PTCA }(n=9)\end{array}$ \\
\hline 7 day mortality & $103(70 \%)^{\star}$ & $10(26 \%)$ & $4(12 \%) \dagger$ & $7(78 \%)$ \\
30 day mortality & $122(83 \%)^{\star}$ & $15(39 \%)$ & $8(24 \%) \dagger$ & $9(100 \%)$ \\
1 year mortality & $130(88 \%)^{\star}$ & $18(46 \%)$ & $11(33 \%) \dagger$ & $9(100 \%)$ \\
\hline
\end{tabular}

Values are $\mathrm{n}(\%)$

${ }^{\star} \mathrm{p}<0.0001$, no PTCA $v$ PTCA; $\nmid \mathrm{p}=0.001$, successful $v$ unsuccessful PTCA.

previous myocardial infarction $(29 \%$ v $41 \%$, $\mathrm{p}=0.1)$, but were more likely to smoke $(36 \%$ v $16 \%, \mathrm{p}=0.007)$. Consequently, as shown in table 5 , the seven day ( $26 \%$ v $70 \%)$, 30 day $(39 \%$ v $83 \%)$, and six month mortality rates $(46 \%$ v $88 \%)$ were significantly lower among patients selected for PTCA than among those not selected $(p<0.0001)$. This benefit persisted after adjustment for age, sex, and history of hypertension for mortality after seven days (OR $0.15,95 \%$ CI 0.06 to 0.34 ), at 30 days (OR $0.14,95 \%$ CI 0.06 to 0.32 ), and within six months (OR $0.14,95 \%$ CI 0.06 to 0.33 ). For the nine patients in whom patency of the infarct related artery was not achieved during PTCA, mortality was significantly higher at all follow up end points and was $100 \%$ at 30 days (table 5). Patients who were treated with IABP experienced lower seven day $(38 \% v 69 \%$, $\mathrm{p}<0.001)$ and six month mortality $(63 \% v$ $86 \%, \mathrm{p}<0.001)$ than patients who were not treated in this way. The survival benefit associated with IABP remained significant at six months after adjustment for age and sex (OR $0.39,95 \%$ CI 0.17 to 0.85 ).

\section{Discussion}

The major finding of our study is that mortality after acute myocardial infarction complicated by cardiogenic shock is lower in hospitals with catheterisation facilities than in hospitals without such facilities. The greater use of invasive and interventional procedures in hospitals with catheterisation facilities is associated with improved survival of patients with acute myocardial infarction complicated by cardiogenic shock.

The results of our study are consistent with the findings of Holmes and colleagues from the GUSTO-I trial. ${ }^{6}$ They found an improved 30 day outcome of cardiogenic shock patients in the USA compared with other countries, and suggested that this advantage might be related to the frequent use of invasive interventions in US patients. Our findings support and extend the observation of the GUSTO-I investigators and indicate that the benefits of catheterisation facilities are also present in a non-selected patient population. Compared with the GUSTO-I results, our patients had a higher percentage of cardiogenic shock on admission (56\% v 11\% among GUSTO-1 patients) and were more likely to have adverse prognostic factors such as older age (70 $v 68$ years), more women $(41 \% v 39 \%)$, and a higher prevalence of diabetes mellitus (41\% v 19\%) and previous infarction (38\% $v 25 \%) .{ }^{46}$ These differences, which emphasise the fact that our population was unselected, may also partially explain the higher mortality in our study compared with previous reports. ${ }^{4}$

The prospective randomised SHOCK trial ${ }^{1}$ evaluated the effect of early revascularisation as compared to the initial medical stabilisation in cardiogenic shock. The SHOCK investigators reported that the primary end point-30 day all cause mortality of a subgroup of patients younger than 75 years of age - was significantly reduced by immediate revascularisation. This benefit became significant for all patients six months after they developed shock. The results of this important study suggest a relation between emergency revascularisation and outcome, thus strengthening the findings of the present study: that on-site catheterisation facilities increase the utilisation of such resources and are associated with improved outcome of patients with cardiogenic shock.

Our study confirmed other observations ${ }^{2} 39$ suggesting that patients with cardiogenic shock who were selected for PTCA had better baseline characteristics and improved short and long term outcome compared with patients who were not selected for this treatment. This outcome benefit remained significant even after adjustment for baseline characteristics, and was more significant for patients with successful PTCA or insertion of an IABP.

\section{LIMITATIONS}

Our findings should be interpreted with caution as this was a post-hoc analysis and therefore subject to the limitations of such studies. Other factors such as nursing skills, hospital volume, and operator experience might have influenced the outcome. The decline in the benefit associated with treatment in hospitals with catheterisation facilities by six months may be related to the relatively low rates of invasive therapeutic intervention performed in these hospitals (19\% PTCA and 24\% IABP), compared with the higher rates in previous reports (up to $48 \%$ PTCA and up to $35 \%$ IABP). ${ }^{169}$

CONCLUSIONS AND IMPLICATIONS

Despite the availability of on-site catheterisation facilities and improved survival, mortality from cardiogenic shock remains high. It is possible that the impact of on-site catheterisation facilities on the outcome of cardiogenic shock might have been made more significant by increasing the proportion of patients transferred for immediate PTCA and by the use of stents and IIb/IIIa receptor antagonists in high risk coronary interventions. Substantial improvements in the management of cardiogenic shock will result from organisational and logistic changes which may lead to rapid and more widespread use of invasive treatments in these high risk patients with acute myocardial infarction. This work formed part of the MD thesis requirements of IMB
at the Faculty of Health Sciences, Ben-Gurion University. The work was supported by grants Nos 95-294 and 98-414 from the United States-Israel Binational Science Foundation (BSF), and grant No 3619 from the Ministry of Health Sciences.

\footnotetext{
1 Hochman JS, Sleeper LA, Webb JG, et al. Early revascularization in acute myocardial infarction complicated by cardiogenic shock. SHOCK Investigators. Should we emergently revascularize occluded coronaries for cardiogenic shock? N Engl f Med 1999;341:625-34.
} 
2 Gacioch GM, Ellis SG, Lee L, et al. Cardiogenic shock complicating acute myocardial infarction: the use of coronary angioplasty and the integration of the new support devices into patient management. $7 \mathrm{Am}$ Coll Cardiol 1992; 19:647-53.

3 Eltchaninoff H, Simpfendorfer C, Franco I, et al. Early and 1 -year survival rates in acute myocardial infarction complicated by cardiogenic shock: a retrospective study comparing coronary angioplasty with medical treatment. Am Heart F 1995; 130:459-64

4 Berger PB, Holmes DR, Stebbins AL, et al, for the GUSTO-I Investigators. Impact of an aggressive invasive catheterization and revascularization strategy on mortality in patients with cardiogenic shock in the global utilization of streptokinase and tissue plasminogen activator for occluded coronary arteries (GUSTO-I) trial Circulation 1997:96:122-7.

5 Bengtson JR, Kaplan AJ, Pieper KS, et al. Prognosis in cardiogenic shock after acute myocardial infarction in the intervention era. $7 \mathrm{Am}$ Coll Cordial 1992;20:1482-9.
6 Holmes DR, Califf RM, Van de Werf F, et al. Difference in countries' use of resources and clinical outcome for patients with cardiogenic shock after myocardial infarction: results from the GUSTO trial. Lancet 1997;349:75-8.

7 Walters MI, Norell MS. Post-infarction cardiogenic shock: is there an evidence base for new management strategies in the late 1990s. Acute Coronary Syndrome 1998;1:52-8.

8 Gottlieb S, Goldbourt U, Boyko V, et al. Improved outcome of elderly patients ( $>$ or $=75$ years of age) with acute myocardial infarction from 1981-1983 to 1992-1994 in Israel. The SPRINT and thrombolytic survey groups. Circulation 1997;95:342-50.

9 Hochman JS, Boland J, Sleeper LA, et al. Current spectrum of cardiogenic shock and effect of early revascularization on mortality. Results of an international registry. SHOCK registry investigators. Circulation 1995;91:873-81.

10 SAS Institute. SAS/STAT user's guide, 4th ed, version 6. Cary, NC: SAS Institute Inc, 1989.

\section{IMAGES IN CARDIOLOGY}

\section{Chronic thromboembolic pulmonary hypertension in a patient heterozygous for both factor $\mathrm{V}$ Leiden and G20210 prothrombin mutation}

A 32 year old man presented with shortness of breath following spontaneous left lower extremity deep venous thrombosis and subsequent multiple pulmonary emboli, documented with ventilation-perfusion lung scintigram. He had no previous medical history of this nature.

Despite adequate anticoagulation the patient gradually developed signs of right ventricular failure with bilateral lower extremity pittingoedema and hepatomegaly. Cardiac examina-

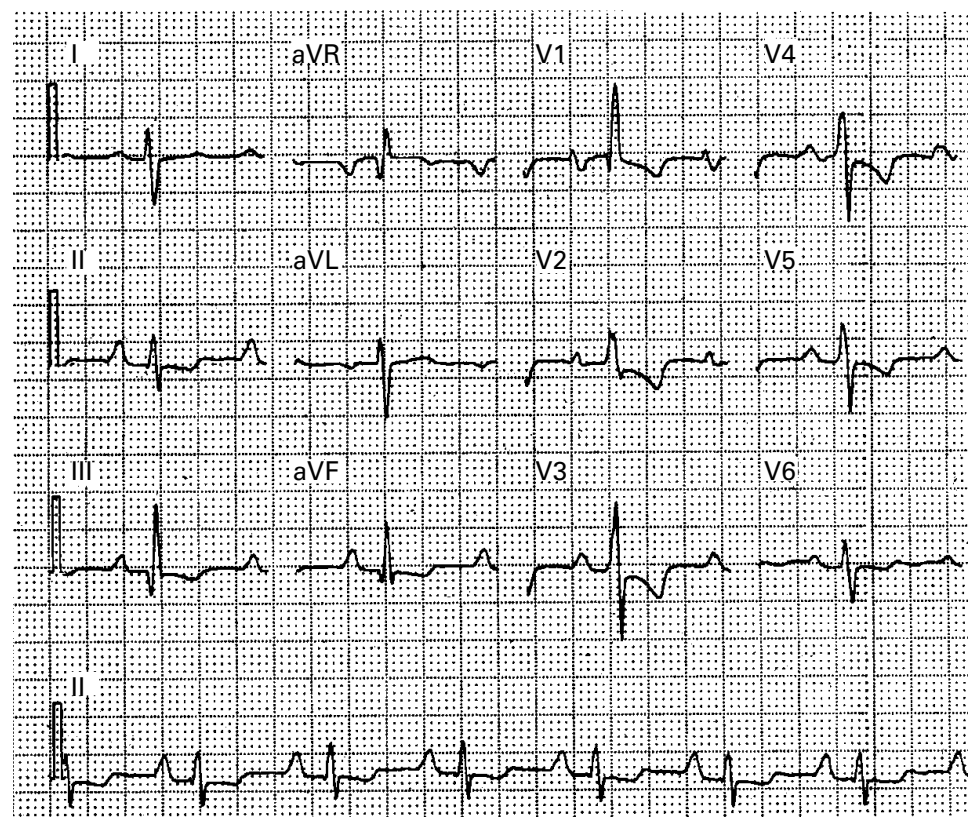

tion was significant for a left parasternal lift, a loud S2, and a third heart sound. An ECG (below) revealed right ventricular hypertrophy with secondary ST and T wave changes, right axis deviation, as well as right and left atrial hypertrophy. An echocardiogram revealed the presence of severe pulmonary hypertension with an estimated systolic pulmonary artery pressure of $80 \mathrm{~mm} \mathrm{Hg}$, right ventricular dilatation, and a right ventricular ejection fraction of $30 \%$. A second ventilation-perfusion scan was consistent with extension of the previously noted perfusion defects, and an inferior vena cava filter was placed. The pulmonary angiogram revealed multiple proximal and distal defects in branches of both pulmonary arteries. An attempt to lyse the thrombi with intravenous streptokinase did not improve pulmonary artery pressures, or the patient's symptoms.

The patient underwent successful pulmonary endarterectomy which confirmed the diagnosis of thromboembolic pulmonary hypertension and led to subjective and functional improvement.

During an investigation for hypercoagulable state the only abnormality detected was a double heterozygosity for factor V Leiden and the G 20210 prothrombin mutation genes. This association is reported for the first time as causing thromboembolic pulmonary hypertension.

E S BRILAKIS A N MANGINAS D V COKKINOS 